\title{
Examining modus operandi in stranger child abduction: a comparison of attempted and completed cases
}

Craig J. R. Collie \& Karen Shalev Greene

\begin{abstract}
Existing inquiries purporting to study and describe offender behaviour in stranger child abduction (SCA) have utilized an overly narrow definition of modus operandi (MO), focusing only on very outset of the offence. The study aims to reflect changes that occur as the offence proceeds, and to examine whether differentiating between attempted and completed cases can provide greater understanding of MO in SCA. The MO utilized by offenders in 78 cases of SCA retrieved from publicly available UK sources were examined. Descriptive analysis was used to determine which types of behaviour were present. Multidimensional scaling was used to categorise these behaviours and to establish whether any relationships existed between them, with view to ascertaining whether there were any clear patterns among strategies. Results found support for differentiating attempted and completed offences, with the analysis highlighting that offenders who utilized multiple means of control, who were more aggressive, and who shifted their MO from one theme to another, were more likely to complete the offence. The study concludes that more nuanced categorisations of SCA offending approaches, which reflect change over time, are required, and argues for additional, contextual information to be incorporated into future work.
\end{abstract}

\section{Introduction}

The abduction of a child by a stranger is relatively rare, with the most recent figures indicating that 247 cases were reported to UK police in 2013 (Newiss \& Traynor, 2013). In perspective, the Office for National Statistics recorded 531,000 incidents of stranger perpetrated violence in 2017 (ONS, 2017). Furthermore, 75\% of the 247 reported case were attempted offences where the child was not abducted. Despite this relative rarity, each 
incident of stranger child abduction (SCA) presents risk of potential serious harm for targeted children (Finkelhor, Hotaling \& Asdigian, 1995; Asdigian, Finkelhor \& Hotaling, 1995; Boudreaux, Lord \& Dutra, 1999). Despite this, SCA has been subject to relatively little empirical research. A large proportion of studies have been concerned with establishing overall incidence of SCA (Finkelhor, Hammer \& Sedlak, 2002; Finkelhor \& Ormrod, 2000; Miller, Kulrycheck, Hansen \& Wilson., 2008). Coverage of behavioural information tends to be broad and descriptive (see Shutt et al, 2004; Noor-Mohammed, 2013). Only very recent studies have examined these offenders and their behaviours in greater detail (e.g., Tillyer, Tillyer \& Kelsay, 2015), but such studies have not used the opportunity to consider the implications of these details for offender modus operandi (MO). Further to this, one of the few papers suggesting models by which to group the MO of SCA offenders, by Tedisco and Paludi (1996) can be criticised for basing their conclusions on general observations of cases rather than structured study. Their argument to adopt the 'lure' and 'blitz' offence categorisations therefore requires testing, with the current paper hoping to examine the appropriateness of this grouping when examining verifiable cases.

In order to investigate offender behaviour more fully, this study pays special attention to whether the offences in question were attempted or completed (Gallagher, Bradford \& Pease, 2008; Newiss \& Traynor, 2013). Very few studies have mentioned how abduction incidents end (e.g., Finkelhor \& Ormrod, 2000), and those that do have not discussed the mechanisms that explain how or why the offence ended in that manner. Differentiating attempted and completed cases has been identified as a possible key to understanding how best to prevent SCA (Newiss \& Traynor, 2013), and this paper will test this assertion by examining whether different offending profiles will be produced for attempted cases when compared to completed ones. 
The aims of this paper are therefore twofold: first, it intends to conduct a thorough examination of MO utilized in SCA with a view to ascertaining whether currently used offending themes are appropriate, with the sub-aim of ascertaining whether previously indicated strategies and motives (discussed below) can be verified; second, it compares the MO utilized by offenders responsible for attempted cases and for completed cases, with the purposes of ascertaining whether there are key trends in behaviour that can determine how a case will end.

Before proceeding, it is necessary to define key terms. 'Stranger' is defined as referring to a situation in which the victim and offender have had no prior contact or familiarity (Newiss \& Traynor, 2013). This distinguishes stranger abductions from acquaintance abductions and "known, not related" cases where there has been some prior awareness between parties, and which are generally studied separately from stranger cases (Finkelhor \& Ormrod, 2000; Newiss \& Traynor, 2013). A 'child' is anyone under the age of 18 (Home Office, 2010; Eales, 2015). Abduction refers to an act intended to remove a child from the control of their lawful guardian, whether attempted or completed (Child Abduction Act, 1984). For the purposes of the present analysis, an abduction is deemed to have been an 'attempt' when a stranger appears to have taken some active steps towards abduction of a child, but either they were interrupted, they aborted their efforts, the child did not go with them, or some other circumstance occurred that prevented the child from actually going missing (e.g., Collie \& Shalev Greene, 2016; Newiss \& Fairbrother, 2004). If the child was moved or detained- for any duration and by any distance- the offence was considered 'completed'. This low research threshold for offence completion reflects the low legal threshold for ascertaining guilt in abduction cases.

\section{Modus Operandi}


MO has been defined as "all of the behaviours that are requisite to a particular offender successfully perpetrating a crime" (Hazelwood \& Warren, 2004, p.308), clarified as equating to the "how to" of an offence and applied to offences was attempted rather than "successful". Although primarily examining offender action, an MO can also refer to the way in which an offender achieves their goal, e.g., it can include reference to use of tools and weapons, or to what an offender says (Leclerc, Proulx \& Beauregard, 2009; Turvey, 2008). Importantly, MO can also refer to the sequence of actions taken by the offender as the crime progresses and whether they exhibit any behavioural change; it is not purely a snapshot of what they were doing at the outset of the offence (Beauregard et al., 2008). As such, an examination of MO ought to be dynamic and account for change (Leclerc, Proulx, Lussier \& Allaire, 2009). Existing studies of SCA have not examined MO fully, but rather have focused on the offender's initial method of approach (Lanning \& Burgess, 1995; Tedisco \& Paludi, 1996; Finkelhor, Hammer \& Sedlak, 2002). This is problematic, as discussions of MO as they pertain to other, similar offences have developed to include consideration of a full range of offender strategies and behaviours. In particular, literature on sexual offending against children developed considerations of how an offence develops and how it concludes, indicating that offences ought to be viewed as continuous events and not restricted to a snapshot approach that considers only the first actions an offender takes (Beauregard et al., 2008). It is argued that a more thorough consideration of how offences develop, and how they conclude, is required to bring perspectives on MO in SCA in line with other areas.

\section{Stranger Child Abduction}

There is evidence to suggest that stranger cases differ from acquaintance and parental cases (Asdigian, Fineklhor \& Sedlak., 1995). The most notable MO variation relates to the location of offending, with stranger cases occurring predominantly outdoors, whereas 
acquaintance and parental abductions generally occur in private (Miller et al., 2008;

Boudreaux, Lord \& Dutra, 1999). This paper focuses on incidents of SCA carried out by male offenders, as it has been recognized that female perpetrated SCA is of a unique characteralmost exclusively relating to abduction for purposes relating to maternal desire rather than sexual, violent or monetary motives - that ought to be studied in isolation (Ankrom\& Lent, 1995; Baker, Burgess, Rabun \& Nahirny, 2002). Furthermore, no female perpetrated cases meeting the inclusion criteria were detected during data collection.

Although SCA can occur for many reasons, including ransom or revenge (see Wolak, Finkelhor \& Sedlak, 2011), this paper follows the approach utilised by Newiss and Traynor (2013)- while it can be difficult to positively ascertain motive in abduction cases, $100 \%$ of both the attempted completed cases found by Newiss and Fairbrother (2004), where evidence was available, were found to be sexually motivated. Therefore, sexual motive is assumed when there is an absence of evidence to the contrary. This perspective was recently affirmed by Tillyer, Tillyer and Kelsay (2015).

\section{Modus Operandi and Stranger Child Abduction}

The most commonly occurring terms referring to MO in SCA are "lure" and "blitz" (Tedisco \& Paludi, 1996; Hanfland et al., 1997). The term 'lure' describes a general approach used by the offender where some tactic or pretence was utilized in order to convince the victim to accompany them. Leclerc, Proulxand Beauregard (2009) identify the key features of the lure as involving the replication of "pro-social behaviours", demonstrating "love, attention [or] appreciation" towards the intended target. The lure has been connected to exploiting the socially encouraged subordination of children to the authority of adults 
(Johnson et al, 2006) as well as the predisposition of certain children to trust; a trait which offenders learn to identify, nurture and exploit (Wortley \& Smallbone, 2006; Webster, 2012). The weight of literature therefore suggests that one of the hallmarks of the lure approach is a lack of overt aggression.

Tedisco and Paludi (1996) identified three key themes relating to the rationale behind lures: appeals to authority which exploit the tendency of children to defer authority to adults (Warden, Moran, Gillies, Mayes \& Macleod, 1997); appeals to empathy exploit the fact that children are usually taught to be kind and to help others (see Newiss, 2014); and appeals to familiarity describe attempts by the offender to make it seem as though the victim knows or should know them. Although most lures are likely to involve some degree of speech in order to gain compliance, an offender can use non-verbal cues, such as smiling, or actions such as beckoning a child in order to facilitate movement (Wortley \& Smallbone, 2008).

The alternative type of approach identified in SCA has been referred to as a "blitz" attack (Hanfland et al., 1997). Burgess and Holstrom (1984) defined a blitz attack as being where the offender appears and attacks the victim suddenly. Burgess later defined the blitz as an attack where there was "no previous interaction of any kind between the assailant and the victim" (p.392). A blitz has been characterized as being intended to surprise and overwhelm the victim using sudden aggression (LeBeau, 1987). The blitz style of offence has also been associated with suddenness and the use of weapons by an assailant (Bondurant, 2001), and the threatening of physical violence (Kahn, Mathie \& Torgler, 1994). In contrast to lures above, the weight of literature here appears to indicate that a key feature of 'blitz attacks' is coerciveness and aggression. This creates the possible implication that one of the main ways in which offences are being compared is the level of aggression used. 
In terms of particular strategies used, blitz attacks have been characterised as including "surprise attacks", defined as occurring against an unaware victim where the offender attacks from behind or from concealment (Hauffe \& Porter, 2009, p.489). Another is a trend in assaults where the offender briefly asks the victim a question- e.g., asking the timewith the purpose of causing the victim to stop moving in order to create an opportunity for attack (Cheshire, 2004, p.673). Other less common types of aggressive strategy have been identified in"child safety materials", which are teaching materials aimed at children and carers in the form of pamphlets (NCMEC, 2013; 2015) and educational videos (e.g., GMP, 2015). The strategies identified include the "feigned injury" or "accident trick" (e.g., by WCOT, 2009), where it is suggested that the abductor might pretend to be debilitated and then grab a child who approaches them to offering assistance. Aside from the surprise attack, these tactics do include some level of trickery in addition to the assault, creating a limited overlap with lures.

The 'lure' and blitz' typologies are portrayed as diametrically opposed by Tedisco and Paludi (1994) in relation to child abduction. However, while some other research does appear to imply these are separate phenomena (e.g., Salfati et al, 2015), the two terms are not necessarily portrayed as being so mutually exclusive in literature pertaining to other offence types- in particular these typologies have been used to discuss assaults and sex crime perpetrated by strangers. In particular, 'blitz' attacks are often discussed alongside what is referred to as a 'con approach' (e.g., Dalley \& Ruscoe, 2003). Definitions of a 'con approach' have been inconsistent- for some it refers to an ongoing campaign of becoming familiar with a victim to gain access (Dalley \& Ruscoe, 2003), while for others it is a shorter interaction or pretext preceding an attack (Fritzon \& Ridgway, 2000). This overlap is best characterised by 
Canter (1996), where the 'blitz' variable could occur whether preceded by a confidence approach or not- this indicates the potential for an overlap to occur.

It is one of the contentions of the current paper that, especially in the context of SCA, that these distinct categories, despite being reported as having some overlap, may still be treated as overly separate. The paper has the following hypotheses: first, it expects to find that attempted and completed SCA will have different profiles in terms of offender strategy and approach; second, it anticipates that the 'lure' and 'blitz' typologies will not adequately explain SCA when accounting for factors beyond the initial offending strategy, e.g., when conceptualising the offence as an ongoing process.

\section{Methodology}

\section{Method}

This study used quantitative secondary data analysis of a series of 78 SCA cases that were committed in the UK. The primary types of data-source used were court transcripts and newspaper articles reporting on offences and their related court trials. In the UK, the transcripts of most legal hearings are not made available unless they alter legal precedent. This makes media reporting on legal proceedings the most direct data available for the majority of trials. An attempt was made to gain access to police records as well; however, the recording practices in the database used made it impossible to differentiate stranger and acquaintance cases.

The use of media archives and newspaper reports has been used to facilitate other studies: Newiss and Greatbatch (2017) utilized media reports from tabloid and broadsheet outlets to determine features of cases where adults went missing on a night out. The current 
study similarly utilizes media reports (additionally supplemented by legal reports) to establish offender movement, activity and behaviour. LaFree \& Dugan (2007) used media reports to create an offender database for terror offences, as data on such cases from official sources tends to be limited. This situation is strongly reflected for SCA, where official data is inconsistently coded- a series of studies by Newiss uncovered inconsistent recording practices between individual UK police forces (Newiss \& Collie, 2014; 2016; Newiss, 2015).On this matter, Lafree and Dugan (2007, p.182) additionally make the point that police and other official databases, which are the traditional source of data for such studies, are subject to biases of their own, i.e., they might reflect police operational priorities and therefore selectively report information (LaFree\& Dugan, 2007, p.182).

Legal cases were gathered by searching the legal databases Westlaw and Lexis using various combinations of the terms 'Stranger', 'Child', 'Abduction', 'Sexual', 'Assault' and 'Kidnap'. Media reports were gathered by searching the specialised database Lexis, as well as the open resource search engines Google and Yahoo. The same key words were used, with the additional terms 'Charged', 'Guilty', and 'Convicted'. Fifty-six outlets were identified and searched (see Table 1). The terms "Sexual" and "Assault" were utilized due to UK rules of primacy mean that cases of abduction that go on to feature another type of offence will be recorded as that more serious case (see Newiss \& Traynor, 2013). Using these terms made it possible to review a wider range of reports in order to examine whether an abduction had occurred as part of their commission.

Measures were taken to assist in ensuring as much validity as possible when using secondary information: Only cases involving a confirmed conviction were analysed.

In total, this search resulted in identification of 187 sources that were used to provide the information present in the finalized database. Of these, 32 were court case transcripts, and 155 were newspaper reports. The number of newspaper sources for each offender ranged 
from 1 to 9 , with a mean of 2.7 sources per offender. Those cases with 1 media source had an accompanying court case transcript. Court transcripts were available for 24 offenders, with a range of between 1 and 3 reports per offender.

[Insert table 1 here]

Cases were only included where there was no indication that the offender and the victim had any contact with one another prior to the incident. There was a single case where a repeat offender abducted the same victim on two separate occasions.

\section{Coding}

Using these sources, information relating to each incident was compiled into individual files, including as much detail as possible and utilising the original wording of the reports. This was done to organise the material with a view to putting information for each case as close to a chronological order as possible, and the enable corroborating (or conflicting) statements to be easily viewed. These profiles were the used to code for the presence of 23 variables (see Table 2 for details), identified from a literature review, pertaining to offender's MO in SCA and related cases, alongside information relating to victim age, victim sex, offender age, and offence outcome. Limitations on space prevent a detailed account of all literature accessed being provided, but key texts include: Tedisco \& Paludi, (1996); Lanning and Burgess (1995); Hanfland, Keppel \& Wies (1997); Finkelhor, Hammer \& Seklak (2002); Boudreaux, Lord \& Dutra (1999); Boudreaux, Lord \& Etter (1995_; Leclerc, Proulx \& Beauregard (2009); Wortley \& Smallbone (2006); Webster et al, (2008); Proulx Perreauls \& Oimet, (1999); Hayden \& Dlugosz,(2011); Finkelhor, Hotaling \& Sedlak (1992); Best (1987; 1989); Lecllerc, Smallbone \& Wortley, (2008); Moran et al, (1997); Newiss, (2014); Newiss \& Traynor (2013); Olsen-Woods et Al, (1998); Johnson et. 
Al. (2005); Poche et al (1981); Burgess and Holstrom (1984); Hauffe\& Porter, (2009);

Bodurant,( 2001); Kahn, Mathie\&Torgler (1994); Cheshire (2004), LeBeau (1987);

Hakkanen, Lindlof\&Santtila (2004); WCOT (2013); Shutt et al, (2004).

Variables were coded dichotomously, based on whether they were present or not during the offence. The coding process was primarily carried out by the first researcher as part of a larger study of SCA cases.

The coding for 'manipulative' requires additional clarification. For this variable to be coded as present, the first action taken by the offender to facilitate the crime had to be a verbal or non-verbal effort to have the child follow them. Any non-violent or non-threatening means of facilitating the abduction was considered to be manipulative.

[Insert Table 2 Here]

Inter-rater reliability was established by having the second author evaluate the coding frame by examining each code and its parameters, using the original framework established by the primary researcher. Subsequently, the coding frame was used to recode every $5^{\text {th }}$ case in the sample, utilizing the narrative vignettes, original media articles and legal transcripts. No disagreements were found, so no further development or revision of the content dictionary was necessary.

The variables were coded and entered into IBM SPSS version 22 for the purpose of analysis. Multi-Dimensional Scaling (MDS), a form of statistical test that measures the level of correlation present between a collection of variables, was used. This approach has the advantage of being able to depict the structure of a dataset visually in the form of a plot. MDS, along with several tests derived from it, such as Small Space Analysis (SSA), are 
commonly utilized by investigative psychologists to examine various facets of offending behaviour and decision making (Goodwill et al., 2012). MDS is capable of depicting similarities and dissimilarities between variables (Sturrock \& Rocha, 2000). The current study is an analysis of similarities. Multidimensional scaling is the most appropriate method of grouping variables given its focus on correlation coefficients between variables, which made up for the relatively small sample size that would have reduced the predictive power of logistical regression and other similar alternatives. It is also the most appropriate test to use when variables are nominal/dichotomous, as all were in this study (Canter et al., 2003).

In order to identify additional variables for study, the dataset was subjected to a process of "thematic interpretation" (Braun \& Clarke, 2006). Thematic interpretation is a subtype of thematic analysis, and is used to develop themes and sub-themes from data. From this, two additional variables were identified. These variables were "front loaded control", which refers to offenders utilizing multiple strategies early in the offence, and "shift", which refers to offenders whose offending strategy shifted from manipulative to aggressive means or vice versa, during the offence. These were subsequently coded quantitatively.

Before embarking with the MDS tests, linear regression was carried out to examine whether case completion could be predicted using the set of variables identified. The same 21 variables as would be used for MDS were entered into such a test using SPSS. The results indicated that the set of variables resulted in a very large R of .944 and R Square of .851. The F statistic was 21.612 , which is very high, with a $\mathrm{p}$ value of less than 0 .

The MDS tests were then carried out, using Jaccard's coefficient to measure distance and establish similarity between variables. Jaccard's coefficient is one of several ways in which the similarity between variables can be assessed, and takes account of only positive co- 
occurrence (Jaccard, 1908). This approach was chosen as it best suits what Goodwill at al. (2012, p.96) calls "messy behavioural data", as appears in this study. It is among the most commonly used method used to assess similarity in studies utilizing MDS of offender behavioural patterns, including examinations of stranger perpetrated sexual offences (e.g., Canter, Bennell, Alison \& Reddy, 2003). Jaccard's measure ranges from 1 to 0 with 1 being total co-occurrence, and 0 indicating no co-occurrence whatsoever.

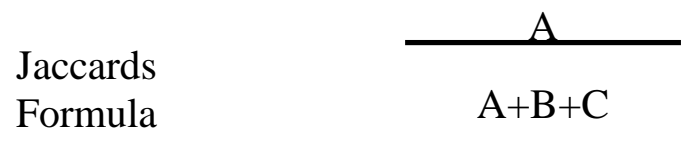

(Adapted from Goodwill, 2012)

The similarity matrices produced by Jaccards measure of association were used to carry out the Multidimensional Scaling test that resulted in Figures 1 and 2.

Following this, additional descriptive and inferential tests including cross-tabulation, Pearson's Chi-Square, and Spearman's R were used to establish frequencies of key behaviours present within each of the themes identified, and to further examine associations between variables.

\section{Sample Description}

The offenders $(n=53)$ represented in this sample were exclusively male. Their ages ranged 18-59 years, with an average age of 35.05 (SD 10.582). The media age was 31 years, and the mode was 29 years. 
In total there were 83 victims. Where age was known $(n=75)$, the average age was 10.68 years, with a standard deviation of 2.97 and a range of 2 to 17 . The median was 11 years and the mode was 10 years. In terms of grouping, 31 victims were aged 0-10 (41.3\%), 36 were aged $11-14(48.0 \%)$, with $8(10.7 \%)$ aged $15-17.35 \%(n=27)$ of cases were attempted abductions, and $65 \%(n=51)$ were completed abductions.

The discrepancy between number of offenders and number of victims is due to there being cases with multiple victims, and because some offenders were responsible for multiple incidents. For cases involving more than one victim: 5 cases had 2 victims; and 1 case had 3 victims. 8 offenders were responsible for more than a single offence: 4 offenders were responsible for 2 separate incidents apiece; 1 offender was responsible for 3 separate incidents; 1 offender was responsible for 4 incidents apiece; and 2 offenders were responsible for 5 incidents apiece. No incident involved both a repeat offence and a team offence.

The offenders received a variety of convictions, some of which were paired with convictions for child abduction or kidnap, and some of which, due to the rules of primacy, did not acknowledge the abduction behaviour. Table 3 shows the primary convictions given to each offender. Aside from involving abduction behaviour, the offences were predominantly sexual in nature.

[Insert Table 3 Here]

\section{Results}

\section{Multi-Dimensional Scaling Results and Preliminary Analysis}


[Insert Figure 1]

\section{Figure 1: Multidimensional Scaling for Attempted Cases}

Figure 1 displays the MDS output for behaviours present in attempted cases. There was good fit, with an s-stress score of .0134 (Dugard, Todman \& Staines, 2010). How well the MDS output represents and accounts for the dataset is represented by the measure of stress (Sturrock \& Rocha, 2000, p.19). Kruskal and Wish (1978) suggested that a score of lower than 0.10 would account for an adequately close fit, a requirement which this test met. Additionally, Tuckers coefficient of congruence showed a score of .994, with the variance accounted for showing a score of 0.989. Dugard et. al (2010, p.275) explain that these values should be as close to 1 as possible, which again, the scores for the current test are. The multidimensional scaling test for attempted cases of SCA carried out 57 iterations, with a final normalised raw stress value of 0.010 . This is quite a high number of iterations, indicating an uncertain initial fit which was improved dramatically via iteration, with a final good fit. Overall, the data for this analysis appears to have good of fit.

The scatterplot shows the similarities between variables, and is a visual representation of the Jaccard Index, which shows the similarity or correlation between variables in numerical format. Shorter distances between variables on the scatter plot represent higher similarity, and a greater likelihood of co-occurrence in the same case, while the correlation coefficients express similarity as closeness to 1 (see Wickelmaier, 2003). Where variables are clustered together in particular areas of the graph, this indicates homogeneity between those variables, and distinguishes them from variables appearing elsewhere on the plot. 
From this, the first notable finding is that offence tactics were grouped in a distinct manner with characteristics representative of manipulative MO tending towards the right of the graph, and those relating to an aggressive approach tending towards the left. Themes were identified by examining the proximity of variables to one another, with particular importance being placed on the positioning of the manipulation variable and grab variables, which can be considered to broadest explanations of offender approach. There was clustering around these variables, indicating that manipulation was achieved using mostly verbal means, with manipulativeness and conversation reporting a correlation coefficient of 0.5 . Forceful movement was facilitated by physical means or threatening behaviour, with grabs correlating to threats (0.462) and, as one might expect, to assault (0.643). Efforts to grab the victim were relatively closely clustered with making threats $(0.462)$, tool use $(0.313)$ and weapon use (0.286) whilst manipulative means were correlated with a conversational approach $(0.500)$. The correlations appear to indicate that manipulative offenders would use one strategy, since the various types of verbal approach, e.g., incentive, using authority, implying familiarity, were not correlated, the only exception being appeals to authority and appeals to familiarity (0.5), indicating that a ruse involving a statement of familiarity implicitly enables offenders to also issue commands to victims. Conversely, aggressive offenders appeared to utilise a combination of measures, with weapons used to enforce threats $(0.455)$, and threats correlating to assaults (also 0.455 ).

Of particular note is the presence of speech for both manipulative and for aggressive offence types, in the form of conversation and threats respectively. This appears to indicate that, while speech was relevant to either approach- indeed, occurred $72.7 \%$ of all offences and during $77.3 \%$ of them- that a joint approach, using both verbal and physical components, was used in aggressive approaches. A final standout finding revealed by the correlation 
coefficients was the role of vehicles in manipulative offense, with coefficients of 0.412 when compared to the manipulative approach and of 0.308 when occurring alongside conversation, itself strongly related to a manipulative approach.

The use of a "one liner" was grouped more closely to aggressive means (grab: 0.231; assault: 0.300 ), with almost no correlation to other strategies, supporting the idea such an approach is a precursor to an assault despite being verbal. The groupings indicate a greater reliance on specific tools by aggressive offenders- weapons were particularly likely to have been brought to a scene $(0.571)$, whereas manipulative offenders are more likely to improvise equipment or to rely on verbal means alone, indicated by the lack of correlation to tools between more manipulative strategies compared to aggressive ones.

[Figure 2]

\section{Figure 2: Multidimensional Scaling for Completed Cases}

Figure 2 shows the behaviours correlated with completed offences. There was a reasonably good fit, with an s-stress score of .0423 (Dugard, Todman \& Staines, 2010). The multidimensional scaling test for completed cases of SCA carried out 14 iterations, with a final normalised raw stress value of 0.028 . Tuckers coefficient of congruence showed a score of 0.985 , with the variance accounted for showing a score of 0.971 . Being close to 1 , these represent a good fit (Dugard et. al, 2010).

The groupings of variables are clearer in this output, with aggressive means being strongly clustered. The correlation statistics for Figure 2 are higher on average than Figure 1, indicating closer groupings. The high level of related variables here reflects offenders using multiple means to control victims, supporting the notion that offenders will front load their 
efforts to control victims. The most immediately apparent feature of this output is that completed cases were more likely to involve highly aggressive, coercive, controlling behaviours. The grabbing of a victim was correlated to threat (0.69), auctioning that threat (0.44), assault (0.71), clear evidence of sexual motive (0.44) tool presence (0.46), and with front loaded control (0.48). Offenders who became violent were more likely to carry out an abduction to completion, as were offenders who used multiple means of control up-front. Additionally, indicators of offender preparedness, such as bringing weapons and tools to the scene, were associated with case completion. The use of aids, particularly tools, were strongly indicative of completion, extending to manipulative offences in the form of incentives (0.61). Conversely, more manipulative means appeared to be less associated with offence completion, especially strategies that are identifiable with "lures" such as appeals to authority, requests for assistance and offers of assistance. That said, this graph had higher correlations between the different manipulative strategies than Figure 1, thus indicating a greater use of multiple strategies in completed cases compared to attempted ones- for instance, requests for assistance also correlated to appeals to authority (0.29) and to use of incentives (0.23)- while not high correlations when compared to some of the other variables in Figure 2, they are far more present than in Figure 1. Additionally, variables such as having more than one victim or more than one offender were less associated with abduction completion. Additional cross-tabulation and chi-square tests were undertaken to check the interpretations of the MDS outputs, supporting the view completed cases were more likely to feature aggressive and controlling behaviour. The presence of threats $(\mathrm{p}=0.04)$, threats which were acted upon $(\mathrm{p}=0.007)$, use of restraints $(\mathrm{p}=0.011)$, use of a tool $(\mathrm{p}=0.033)$, and assault $(\mathrm{p}=0.019)$ were all associated with completed cases. In particular, assaultive behaviour had a $76.74 \%$ completion rate when present against a $51.43 \%$ rate when not. Of particular interest was that $64.71 \%$ of completed cases featured an assault, a highly aggressive type of 
behaviour, whereas only $37.04 \%$ of attempted cases had this feature. Additionally, it was found that front loaded control- which embodies high levels of control efforts within an offence- was highly associated with offence completion ( $\mathrm{p}=0.005)$, with an $85.71 \%(\mathrm{n}=24)$ completion rate where present, and a 54\% $(n=27)$ when not. $47.02 \%(n=24)$ of all completed cases had this feature, which is relatively high within this sample.

A further examination of the frequencies of the presence of aggressive control variables appears to support this position.

[Insert Table 4 Here]

[Insert Table 5 Here]

As these Frequency Tables 4 and 5 illustrate, completed cases involved proportionately far more instances of weapon and tool use than attempted cases, as well as the presence of multiple, aggressive approaches to victim control. Offenders utilizing all means at their disposal, and who resort to overwhelming physical, aggressive control tactics, were more likely to abduct victims.

Within the cases characterized by a manipulative control, the primary strategy utilized by offenders were use of incentives (34.15\%), offer of assistance (24.38\%) and request for assistance (17.07\%) The primary strategies utilized by offenders in cases characterized by aggressive control were grabbing the victim and controlling them by purely physical means (38.71\%), briefly engaging in conversation before grabbing them and launching an assault (32.26\%) and a combination of grabbing the victim and utilizing threats $(22.58 \%)$. 


\section{Shifts in MO}

There was an additional process that could not be captured by multidimensional scaling. There were some cases where offenders changed their overall theme of behaviour during their offending sequence. This change in MO is herein referred to as a "shift" $(n=17)$. $70.5 \%$ of cases featuring shift were completed.

Such a shift occurred predominantly from offenders initially partaking in benign, manipulative mental control, who then progressed to aggressive, physical control and generally aggressive tactics (94.2\%). An example of this involved an offender who convinced the victim to come with him into a secluded wooded area, out of sight from any pathways, who then launched a sudden, violent assault.

Only one case $(5.8 \%)$ saw the reverse: this was an attempted abduction where the victim escaped an initial grab. The offender then followed the victim, attempting to convince her (and nearby third parties) that she ought to accompany him.

The high levels of completion among offenders who shifted from manipulative control to aggressive involved appears to further support the findings from the MDS that aggressive tactics, as well as multiple means of offending, result in higher rates of offence completion. This additionally helps to explain why aggressive and manipulative strategies become more associated in completed cases: this may be a reflection of those offenders who make a transition from one approach to the other during their offence sequence.

\section{Discussion}

This study has sought to take an approach to studying in SCA that reflects the dynamism of the offence, making an effort to examine features of cases that are ongoing, and in particular comparing attempted cases with completed cases. 
The study expected to find that the previously used thematic paradigms of 'blitz' and 'lure' would be of limited usefulness in explaining CRA when this fuller account of the offence was made. Findings have been mixed, in this regard. The themes of 'aggressive' and 'manipulative' offending were used to group offence themes in the multi-dimensional tests. While these appeared to be an appropriate method by which to group strategies, it should be said that 'lure' and blitz' could also comfortably have been mapped to the MDS outputs. Regardless of the label used, offence strategies divided fairly neatly into highly assaultive and highly aggressive approaches, which appeared to be fairly distinct. There is precedent for a similar distinction, with manipulative and coercive offender types being identified by Beauregard et al. (2007), and this study indicates that their model could to be applied to SCA as well the more commonly used lure and blitz, however, the term 'aggressive' is used here to distinguish this type of behaviour from the 'coercive control' construct utilised by Stark in relation to domestic abuse (Stark, 1994; 2009). Aggressiveness is a more appropriate term here since, as Stark's (2009) construct shows, coercive control can be entirely non-violent. That said, however, the results relating to the concept of a 'shift' in offending activity are not captured all that well by the 'lure' and 'blitz' paradigm. While it is acknowledged in the literature review that 'lure' and 'blitz' do not imply exclusivity between the strategies associated with each approach, they do not suitably capture the dynamism present in those cases where an offender 'shifts' between offending approaches. Furthermore, this shift is also not captured well by the alternative 'manipulative' and 'aggressive' paradigms. Therefore, it can tentatively be suggested that future research should explore additional paradigms to use with SCA, especially those enabling change over time to be better captured.

Part of the purpose of the study was to empirically verify which strategies are most commonly present in SCA cases. From a purely descriptive standpoint, it was also shown that 
the offender tactics featured in the review of academic and child safety literature were, for the most part, represented in this study. This usefully confirms that existing literature, although still largely based on supposition, somewhat reflects the realities of SCAs. The findings from this study mean that there is now verified data indicating that offenders are likely to either utilize a very simple lure, a lure involving an incentive, an offer of assistance, or a request for assistance, with some notable exclusions, e.g., feigned injuries and use of sweets as lures were not common (Tedisco \& Paludi, 1996). It is recommended that future research continues to examine strategies used in verifiable cases of SCA in order to build a database of evidence, with a view to replacing these earlier, unverified sources, with the caveat that some of the themes they have used appear to be useful. The results also indicate the presence of strategies relating to 'flattery', which had been highlighted previously by Hedges (2002).

Further to the this, the results of the Multidimensional scaling appear to provide support for the assumption that has been previously made that a significant proportion of SCA cases are sexually motivated (i.e., by Newiss \& Traynor, 2013). Sexual assault was strongly correlated with completed cases of abduction, indicating that carrying out a sex attack is a common variable in SCAs. This is doubly interesting when considered alongside the core themes that emerged from the multidimensional analysis, which showed that offender actions appear to be highly related to control. From this, it seems that SCA is strongly characterized by notions of dominance over the victim. While it is beyond the scope of this paper to enter an in-depth discussion of the psychological and profiling implications of these points, however, they represent fertile ground for future research to examine due to being reminiscent of power/control models of sexual offending which emphasise a need for dominance trumping the need for sexual gratification in sex crime (see Sorochinski \& Salfati, 2008). 
The study also expected to find that examining attempted and completed cases separately would reveal additional dynamics in relation to SCA. This was confirmed by the results, which produced varying profiles between attempted and completed cases. This indicates that future studies of SCA should continue examining attempted and completed cases of SCA separately, as suggested by Newiss and Fairbrother (2006) and by Collie and Shalev Greene (2015, 2016a, 2016b). At the simplest level, this approach has been useful as it goes beyond highlighting which individual strategies are used by offenders in SCA, but it also highlights which particular, single strategies result in the poorest outcomes for victims. The findings do not explain why these strategies are more strongly associated with SCA completion, but by highlighting which strategies are resulting in completion, it becomes possible to research these further, and, potentially, explore why these approaches 'work' more often and attempt to suggest means by which to disrupt them.

More useful still was examining which combinations of strategies were related to case outcome. The most notable finding revealed by comparing attempted and completed cases was that highly aggressive offenders who utilize multiple means of aggressive control are more likely to complete abduction than those offenders utilizing manipulative means or who rely on one or two tactics in approaching a child. Variables that imply offence planning appear to correlate with completed offences. Of particular interest, those offenders who "front loaded" their control, i.e., who used multiple methods of control at the outset of the offence to ensure victim compliance, were most likely to complete an offence. Taken together, these findings have the implication that a key determining factor between attempted and completed cases is the extent to which the victim is overwhelmed, referring not only to sheer force, but also to the compounding effect of various strategies. 
The findings potentially have several implications for the body of literature and policy relating to child safety education. The bulk of this literature is aimed at evaluating training programs aimed at equipping children with skills to recognise, understand and defend themselves against a variety of offences, including SCA (see, for example, Moran et al 1997; Johnson et al, 2006). This research ascertains how well children will actually utilise acquired skills when faced with abduction, with other research (e.g., Collie \& Shalev Greene, 2015; 2016a) finding that resistance by victims can significantly impact on case outcome. It is not suggested that training children can eliminate the risk of SCA, nor that onus should be placed on victims, however, this has been shown to be a potential area where resilience can be built. The current research indicates that some of the premises of this literature may need to be reexamined. In particular, an examination of the literature reveals an implication the offenders will either use manipulative means or aggressive means- therefore, the possibility of an offender 'shifting' between these- and what to do in such an event- is ignored. Furthermore, the weight of child safety approaches focuses on manipulative, 'lure' based offender strategies, and to some extent ignore the existence of aggressive offenders. This is concerning as this research indicated that aggresive offenders complete offences more often.

This raises several questions that should be explored, and which indicate useful directions for future research. In particular, the presence of victim resistance, or any other disruptive element, in cases featuring various offender strategies should be examined. This will allow conclusions to be drawn as to whether, for example, manipulative strategies lead to case attempts because victims can resist them, or members of the public intervene, etc. This will enable a more holistic, even more dynamic picture of SCA strategies to be examined.

The findings also point towards some smaller findings of note that can be used to suggest other directions for future research. In particular, the role of tools is potentially 
extremely important in determining the outcome of SCA cases. Unfortunately, the approach utilized in this study meant it was not possible to fully analyse this feature of the sample beyond mere tool presence. Future research should examine this dynamic, especially with regards to how tools are used. The same was true for vehicle presence, especially in manipulative cases.

\section{Limitations}

The authors recommend caution when reading the conclusions of this study. The data gathered is from second hand media and legal sources which may have reporting biases (Bradley, 1991). This type of data also tends towards more serious, newsworthy cases, meaning the sample is not representative of stranger child abductors overall. In addition, a selection of the media sources used may be prone to sensationalised reporting techniques. These limitations are unavoidable at the time of writing given the limited availability of information on these offenders, and due to the need to corroborate information via the presence of a confirmed criminal conviction of an identifiable offender in the UK courts (see Gallagher et al, 2008; Newiss \& Traynor, 2013). The potential bias of reports is mitigated by the study's focus on offender action, and by the need for these actions to be corroborated across multiple outlets and by more reliable legal proceedings.

It is not possible to be completely certain of the victim-offender relationship in any given case, as previous familiarity may not have been reported. However, during the coding process care was taken to ensure, as far as possible, that such familiarity was absent. The first measure was to specifically search for cases that included the term "stranger" in the headline, report, or case report. As a result, most of the cases included contained indications that there was no previous relationship. Secondly, the study had very narrow inclusion criteria that 
would accept only cases where there was no evidence of familiarity at all; any indication of familiarity led to the case being excluded. Thirdly, as a result of having multiple sources for each case, the chance that an outlet or legal case would mention any previous contact was increased.

It is possible that the treatment of cases with multiple victims, multiple offenders, and offenders who were responsible for more than one incident in the same analysis will have skewed the findings. In particular, it is possible that experienced offenders may behave differently than inexperienced ones, with Collie and Shalev Greene (2017) having found offender experience to impact case outcome in cases of child abduction. While it could, conversely, be argued that such effects may be limited, e.g., because of evidence that key features of modus operandi, as this study examines, do not vary all that much in the same offender's subsequent activities (Sjostedt et al, 2004), such discussion is moot as it has not been possible to meaningfully extricate these cases from the sample or to examine them in isolation due to the overall small sample size- removing such cases meant that no meaningful analysis or comparison of these to the 'regular' cases could take. As such, the most logical way to address these potential issues is to be transparent about their presence. The power of these effects could not be ascertained. It is strongly recommended that future studies, with access to more data, separate and compare these case types.

Finally, as Newiss and Fairbrother $(2004$, p. 5) point out, the detection rate for SCA is very low, with only $13 \%$ of cases resulting in positive suspect identification. With this in mind, it follows that the present study, focusing as it does on identified offenders, reflects a minority of SCA offenders and offences. For now, it remains impossible to capture the remaining $87 \%$ of cases in the level of detail captured here, however the present findings should be conceptualised as reflecting stranger child abductors who were apprehended only. 


\section{Final Discussion}

Overall, the study finds support for existing perspectives on the practical behaviours that have been attributed to stranger child abductors; however, while the paradigms of lure and blitz were found to characterize the strategies utilized by abductors to some extent, issues with how they reflect offence dynamism were highlighted. The research also showed that was a very clear divide occurring between offenders who utilize non-threatening strategies, and those who utilize aggressive, aggressive strategies. While these are similar in many respects to the 'lure' and 'blitz' models, the emphasis on change over time in a similar model previously identified by Leclerc, Proulx and Beauregard (2009), indicates that model may be more appropriate to use in relation to CSA. Future research should consider adopting this model and evaluating its effectiveness.

The study has also shown that more elaborate methods that have been associated with each of these offence archetypes are extremely rare in practice, with simpler approaches being predominantly featured. The complexity of abduction appears, therefore, to lie in the transition between modes of offending rather than in elaborate plans. The present research also highlights the need to explore the circumstances as to why certain strategies result in different outcomes, further indicating a need for an overall more complex, holistic approach to understanding- and responding to- SCA.

\section{References}

Ankrom, L.G., \& Lent, C.J. (1995). Cradle robbers: A study of infant abductors. FBI Law Enforcement Bulletin, September 1995, 17. 
Asdigian, N. L., Finkelhor, D., \& Hotaling, G. (1995). Varieties of nonfamily abduction of children and adolescents. Criminal Justice and Behavior, 22(3), 215-232.

Baker, T., Burgess, A.W., Rabun, J.B., \& Nahirny, C. (2002). Abductor violence in nonfamily infant kidnapping. Journal of Interpersonal Violence, 17(11), 1218-1233.

Beauregard, E., Lussier, P., \&Proulx, J. (2005). The role of sexual interests and situational factors on rapists' MO: Implications for offender profiling. Legal and Criminological Psychology, 10(2), 265-278.

Beauregard, E., Proulx, J., Rossmo, K., Leclerc, B., \&Allaire, J. F. (2007). Script analysis of the hunting process of serial sex offenders. Criminal Justice and Behavior, 34(8), 10691084

Beauregard, E., Stone, M.R., Proulx, J., \& Michaud, P.(2008).Sexual murderers of children developmental, precrime, crime, and postcrime Factors. International Journal of Offender Therapy and Comparative Criminology, 52(3), 253-269.

Bennell, C., \& Jones, N. J. (2005). Between a ROC and a hard place: A method for linking serial burglaries by MO. Journal of Investigative Psychology and Offender Profiling, 2(1), 23-41.

Best, J. (1987). Rhetoric in claims making: Constructing the missing children problem. Social Problems, 34(2), 101-121. 
Best, J. (1989). Dark figures and child victims: statistical claims about missing children. In Images of Issues. (Best, J.). (Ed.). 21-37. New York: Aldine de Gruyte

Bodurant, B. (2001). University women's acknowledgment of rape: Individual, situational and social factors. Violence Against Women, 7(3), 2001.

Boudreaux, M.C., Lord, W.D., \& Dutra, R.L. (1999). Child abduction: Aged-based analyses of offender, victim, and offence characteristics in 550 cases of alleged child disappearance. Journal of Forensic Science, 44 (3), 539-553.

Boudreaux, M. C., Lord, W. D., \& Etter, S. E. (2000). Child abduction: An overview of current and historical perspectives. Child Maltreatment, 5(1), 63-71.

Braun, V., \& Clarke, V. (2006). Using thematic analysis in psychology. Qualitative research in psychology, 3(2), 77-101.

Burgess, A., \& Holmstrom, L. (1979). Rape: sexual disruption and recovery. American Journal of Orthopsychiatry, 49(4), 648.

Canter, D, V. (1996). Multivariate model of sexual offence behaviour: Developments in 'Offender Profiling'. in Psychology in Action. Dartmouth Benchmark Series. Dartmouth Publishing Company, Hantshire, UK, pp. 189-216. 
Canter, D. V., Bennell, C., Alison, L. J., \& Reddy, S. (2003). Differentiating sex offences: A behaviorally based thematic classification of stranger rapes. Behavioral Sciences \& the Law, 21(2), 157-174.

Canter, D., \&Fritzon, K. (1998). Differentiating arsonists: A model of firesetting actions and characteristics. Legal and Criminological Psychology, 3(1), 73-96.

Chesire, J. D. (2004). Review, critique, and synthesis of personality theory in motivation to sexually assault. Aggression and Violent Behavior, 9(6), 633-644.

Collie, C. J. R., \& Greene, K. S. (2017). Examining offender, victim and offence characteristics in cases of stranger child abduction: an exploratory comparison of attempted and completed cases using publicly available data from the UK. Aggression and violent behavior, $35,73-82$.

Dalley, M., \& Ruscoe, J. (2003). The abduction of children by strangers in Canada: Nature and scope. National Missing Children Services.

Dietz, P.E., Hazelwood, R. R., \& Warren, J. (1990). The sexually sadistic criminal and his offenses. Journal of the American Academy of Psychiatry and the Law Online, 18(2), 163-178.

Dugard P, Todman J \& Staines H (2010) Approaching multivariate analysis. A practical introduction. Second Edition. Routledge: New York. This text has example analyses using SPSS. 
Eales, N. (2016). iFind. London: National Crime Agency.

Elliott, I. A., \& Ashfield, S. (2011). The use of online technology in the MO of female sex offenders. Journal of sexual aggression, 17(1), 92-104.

Finkelhor, D., \& Ormrod, R. (2000). Kidnapping of juveniles: Patterns from NIBRS. Washington: US Department of Justice: Office of Juvenile Justice and Delinquency Prevention.

Finkelhor, D., Hammer, H., \& Sedlak, A.J. (2002). Nonfamily abducted children- National estimates and characteristics. Washington: US Department of Justice.

Finkelhor, D., Hotaling, G., \& Asdigian, N. (1995). Attempted non-family abductions. Child Welfare, 34, 941-955

Finkelhor, D., Hotaling, G., \& Sedlak, A. (1992). The abduction of children by strangers and nonfamily members: Estimating the incidence using multiple methods. Journal of Interpersonal Violence 7(2):226-243.

Fritzon, K., \& Ridgway, J. (2001). Near-death experience: The role of victim reaction in attempted homicide. Journal of Interpersonal Violence, 16(7), 679-696.

Gallagher, B., Bradford, M., \& Pease, K. (2008). Attempted and completed incidents of childperpetrated child sexual abuse and abduction. Child Abuse and Neglect, 32, 517-528 
Goodwill, A. M., Stephens, S., Oziel, S., Yapp, J., \& Bowes, N. (2012). Multidimensional latent classification of 'street robbery' offences. Journal of Investigative Psychology and Offender Profiling, 9(1), 93-109.

Greater Manchester Police. (2015). 60 second security- stranger danger. Crime Reduction. Retrieved on $16^{\text {th }}$ October 2016 from http://www.gmp.police.uk/content/section.html?readform\&s=02BAEE119FECBC5580 257961003ADB7B

Häkkänen, H., Lindlöf, P., \& Santtila, P. (2004). Crime scene actions and offender characteristics in a sample of Finnish stranger rapes. Journal of Investigative Psychology and Offender Profiling, 1(1), 17-32.

Hanfland, K.A., Keppel, R., \& Weis, J. (1997). Case management for missing children homicide investigation. Washington: US Department of Justice, Office of Juvenile Justice and Delinquency Prevention.

Hauffe, S., \& Porter, L. (2009). An interpersonal comparison of lone and group rape offences. Psychology, Crime and Law, 15(5), 469-491.

Hayden, C., \& Dlugosz, G. (2011). Secondary school children and the experience of robbery: A survey in three south London schools. Crime Prevention and Community Safety, 14(2), 122-139. 
Hazelwood, R.R., \& Warren, J.J. (2004). Linkage analysis: MO, ritual, and signature in serial sexual crime. Aggression and Violent Behavior, 9(3), 307-318.

Hedges, C. (2002). Missing you already: a guide to the investigation of missing persons. London: Home Office.

Home Office. (2010). The Missing Persons Task Force: A report with recommendations for improving the multi-agency response to missing incidents. London: Home Office.

Jaccard, P. 1908. Nouvelles recherche sur la distribution florale. Bull. Soc. Vaudoise Sci. Nat. 5th Ser.44:223-270.

Johnson, B. M., Miltenberger, R. G., Egemo-Helm, K., Jostad, C. M., Flessner, C., \& Gatheridge, B. (2005). Evaluation of behavioral skills training for teaching abduction-prevention skills to young children. Journal of Applied Behavior Analysis, 38(1), 67-78.

Johnson, B.M., Miltenberger, R.G., Knudson, P., Egemo-Helm, K., Kelso, P., Jostad, C., \& Langley, L. (2006). A preliminary evaluation of two behavioural skills training procedures for teaching abduction preventions skills to schoolchildren. Journal of Applied Behavior Analysis, 39(1), 25-34.

Kahn, A.S., Mathie, V.A., \& Torgler, C. (1994). Rape scripts and rape acknowledgement. Psychology of Women Quarterly, 18(1), 53-66. 
Kaufman, K.L., Hilliker, D.R., Lathrop, P., \& Daleiden, E.L. (1993). Assessing child sexual offenders' MO: Accuracy in self-reported use of threats and coercion. Annals of Sex Research, 6, 213.

Klerks, P.(2003). The network paradigm applied to criminal organizations: Theoretical nitpicking or a relevant doctrine for investigators? Recent developments in the Netherlands. In A. Edwards \& P.Gill. (2003). (Eds.). Transnational organized crime: Perspectives on global security. London: Routledge.

Kloess, J. A., Seymour-Smith, S., Hamilton-Giachritsis, C. E., Long, M. L., Shipley, D., \& Beech, A. R. (2015). A qualitative analysis of offenders' MO in sexually exploitative interactions with children online. Sexual abuse: a journal of research and treatment, 1079063215612442.

LaFree, G., \& Dugan, L. (2007). Introducing the global terrorism database. Terrorism and Political Violence, 19(2), 181-204.

Lanning, K. V., \& Burgess, A. W. (Eds.). (1995). Child Molesters Who Abduct: Summary of the Case in Point Series. National Center for Missing and Exploited Children.

LeBeau, J. L. (1987). The journey to rape: Geographic distance and the rapist's method of approaching the victim. Journal of Police Science \& Administration. 
Leclerc, B., Proulx, J., \& Beauregard, E. (2009). Examining the MO of sexual offenders against children and its practical implications. Aggression and Violent Behavior, 14(1), pp 5-12.

Leclerc, B., Proulx, J., Lussier, P., \&Allaire, J. F. (2009). Offender-victim interaction and crime event outcomes: MO and victim effects on the risk of intrusive sexual offenses against children. Criminology, 47(2), 595-618.

Miller, J., Kurlycheck, M., Hansen, A.J., \& Wilson, K. (2008).Examining child abduction by offender type patterns. Justice Quarterly, 25.

Moran, E., Warden, D., Macleod, L., Mayes, G. and Gillies, J. (1997) 'Stranger-Danger: What do Children Know?' Child Abuse Review. 6: 11-23.

National Centre for Missing and Exploited Children. (2013). Know the rules: Abduction harm and prevention tips for parents and guardians. Missing Kids. Retrieved October $16^{\text {th }} 2016$ fromhttp://www.missingkids.com/en_US/publications/NC60.pdf

National Centre for Missing and Exploited Children. (2015). Knowing my safety rules. Missing Kids. Retrieved May $23^{\text {rd }} 2016$ fromhttp://www.missingkids.com/en_US/publications/NC28.pdf

Newiss, G. (2014). Beyond Stranger Danger: Teaching children about staying safe from SCA. London: Parents and Abducted Children Together. Retrieved August 26 ${ }^{\text {th }} 2015$, from http://www.childabduction.org.uk/index.php/publications 
Newiss, G., \& Collie, C. (2016). Police-recorded child abduction and kidnapping 2014/15: England, Wales and Northern Ireland. London: Action Against Abduction. Retrieved February, 1, 2016.

Newiss, G. (2017). Police-recorded child abduction and kidnapping 2015/16: England, Wales and Northern Ireland. London: Action Against Abduction. Retrieved February, 1, 2016.

Newiss, G., \& Greatbatch, I. (2017). Men missing on a night out: Exploring the geography of fatal disappearances. University of Portsmouth.

Newiss, G., \& Tranynor, M.A. (2013). Taken: A study of child abduction in the UK. London: PACT.

Noor-Mohamed, M. (2013). The definitional ambiguities of kidnapping and abduction, and its categorization: The case for a more inclusive typology. The Howard Journal of Criminal Justice, 53(1), 83-100.

Office for National Statistics. (2017). The nature of violent crime in England and Wales: year ending March 2017. Retrieved from https://www.ons.gov.uk/peoplepopulationandcommunity/crimeandjustice/articles/thena tureofviolentcrimeinenglandandwales/yearendingmarch2017 on 4th June 2018 
Olsen-Woods, L.A., Miltenberger, R.G., \& Foreman, G. (1998). Effects of correspondence training in an abduction prevention training program. Child \& family behavior therapy, 20(1), 15-34.

Poche, C. Brouwer, R., \& Swearingen, M. (1981). Teaching self-protection to young children. Journal of Applied Behavior Analysis, 14(2), 169-176.

Proulx, J., Perreaultt., C., \& Ouimet, M. (1999). Pathways in the offending process of extrafamilial child molesters. Child Abuse: A Journal of Research and Treatment, 11(2), 117-129.

Salfati, C. G., Horning, A. M., Sorochinski, M., \& Labuschagne, G. N. (2015). South African serial homicide: Consistency in victim types and crime scene actions across series. Journal of Investigative Psychology and Offender Profiling, 12(1), 83-106.

Shutt, J. E., Miller, J. M., Schreck, C. J., \& Brown, N. K. (2004). Reconsidering the leading myths of stranger child abduction. Criminal Justice Studies, 17(1), 127-134.

Sjöstedt, G., Långström, N., Sturidsson, K., \& Grann, M. (2004). Stability of modus operandi in sexual offending. Criminal Justice and Behavior, 31(5), 609-623.

Smallbone, S. W., \& Wortley, R. K. (2004). Onset, persistence, and versatility of offending among adult males convicted of sexual offenses against children. Sexual Abuse: A Journal of Research and Treatment, 16(4), 285-298. 
Sorochinski, M., \& Salfati, C. G. (2018). A Multidimensional Approach to Ascertaining Individual Differentiation and Consistency in Serial Sexual Assault: Is It Time to Redefine and Refine?.Journal of Police and Criminal Psychology, 33(1), 63-83.

Stark, E. (1994). Re-presenting woman battering: From battered woman syndrome to coercive control. Albany Law Review, 58, 973.

Stark, E. (2009). Coercive control: The entrapment of women in personal life. Oxford: Oxford University Press.

Sturrock, K., \& Rocha, J. (2000). A multidimensional scaling stress evaluation table. Field methods, 12(1), 49-60.

Tedisco, J.N. \& Paludi, M.A. (1996). Missing children: A psychological approach to understanding the causes and consequences of stranger and non-stranger abduction of children. Albany: State University of New York Press.

Tillyer, M. S., Tillyer, R., \& Kelsay, J. (2015). The nature and influence of the victimoffender relationship in kidnapping incidents. Journal of Criminal Justice, 43(5), 377385.

Turvey, B.E. (2008). Criminal Profiling: An introduction to behavioural evidence analysis ( $\left.3^{r d} E d.\right)$. Burlington, MA: Academic Press. 
Warden, D., Moran, E., Gillies, J., Mayes, G., \& Macleod, L. (1997). An evaluation of a children's safety training programme. Educational Psychology, 17(4), 433-448.

WCOT. (2009). Stranger Danger. Retrieved on $6^{\text {th }}$ May 2016 from https://www.youtube.com/watch?v=ygWs9zrBF-o

Webster, S., Davidson, J., Bifulco, A., Gottschalk, P., Caretti, V., Pham, T., Grove-Hills, J., Turley, C., Tompkins, C., Ciulla, S., Milazzo, V., Schimmenti, A., \& Craparo, G. (2012). European online grooming project (Final report). European Commission Safer Internet Plus Programme, Tech. Rep.

Wickelmaier, F. (2003). An introduction to MDS. Sound Quality Research Unit, Aalborg University, Denmark, 46.

Wolak, J., Finkelhor, D., \& Sedlak, A. J. (2016). Child victims of stereotypical kidnappings known to law enforcement in 2011. Juvenile Justice Bulletin. Washington, DC: US Department of Justice.

Wortley, R., \& Smallbone, S. (2006). Applying situational principles to sexual offences against children. In R. Wortley, \& S. Smallbone. (2006). (Eds.).Situational prevention of child sexual abuse. Child Prevention Studies, 19. Monsey: Criminal Justice Press.

\section{$\underline{\text { Tables }}$}


Table 1: Local and National UK Media Outlets Searched

\begin{tabular}{ccc}
\hline & Media Outlets Searched & \\
\hline The Independent & The Telegraph & The Birmingham Evening Mail \\
The Guardian & Hull Daily Mail & The Northern Echo \\
The Journal & Bradford Telegraph \& Argus & The Mirror \\
BBC News & Gloucester Citizen & The Daily Mail \\
The York Press & Morley Observer & Birmingham Mail \\
Walsall Advertiser & Hastings Observer & Bolton News \\
The Northern Echo & Burnley Express & Newham Recorder \\
Wales News & Welwyn Hatfield Times & Lancashire Telegraph \\
Liverpool Echo & North of England News & Dorset Echo \\
Mancunian Matters & The Sun & North Wales Daily Post \\
Northampton Chronicle \& Echo & Yorkshire Evening Post & Yorkshire Post \\
Express and Star & Huffington Post UK & ITV News \\
Rotherham Advertiser & Doncaster Free Press & Belfast Telegraph \\
Evening Standard & Keighley News & Stroud News \& Journal \\
Sunderland Echo & Wigan Today & Leigh Journal \\
Hull Daily Mail & Western Daily Press & Bristol Post \\
Blackpool Gazette & Bury Times & Manchester Evening News \\
Telegraph \& Argus & Kent and Sussex Courier & Kent Online \\
The Herald & The Glasgow Herald & SWNS.com \\
\hline
\end{tabular}

Table 2: Variables and MDS Abbreviations

\begin{tabular}{|c|c|c|c|}
\hline Abbreviation & Meaning & Abbreviation & Meaning \\
\hline Assault & $\begin{array}{c}\text { Physical Assault } \\
\text { occurred }\end{array}$ & Familiarity & $\begin{array}{c}\text { Offender pretends to } \\
\text { know victim }\end{array}$ \\
\hline FrontLoaded & $\begin{array}{c}\text { Front Loaded } \\
\text { Control, i.e., } \\
\text { control techniques } \\
\text { used at offence } \\
\text { outset }\end{array}$ & Sexual & $\begin{array}{c}\text { Evidence that the } \\
\text { offence was sexually } \\
\text { motivated }\end{array}$ \\
\hline MultiVictim & $\begin{array}{c}\text { Multiple Victims } \\
\text { Offender MO } \\
\text { changed during the } \\
\text { offence }\end{array}$ & BmprovisedTool & $\begin{array}{c}\text { Improvised tool found } \\
\text { at the scene }\end{array}$ \\
\hline Manipulative & $\begin{array}{c}\text { Offender's first } \\
\text { action was } \\
\text { manipulative }\end{array}$ & Weapon & $\begin{array}{c}\text { The offender brought a } \\
\text { tool to the scene }\end{array}$ \\
\hline Grab & Offender's first & Ties & Ties or Restraints were \\
\hline
\end{tabular}




\begin{tabular}{|c|c|c|c|}
\hline Authority & $\begin{array}{c}\text { action was to grab } \\
\text { the victim } \\
\text { The offender } \\
\text { appealed to } \\
\text { authority }\end{array}$ & MultiOffender & $\begin{array}{c}\text { There were multiple } \\
\text { Offenders }\end{array}$ \\
\hline Incentive & $\begin{array}{c}\text { Incentive was used } \\
\text { to facilitate } \\
\text { abduction }\end{array}$ & Vehicle & $\begin{array}{c}\text { A vehicle was used } \\
\text { during the commission } \\
\text { of the offence }\end{array}$ \\
\hline RequestAssistance & $\begin{array}{c}\text { The offender asked } \\
\text { for assistance from } \\
\text { the victim }\end{array}$ & Threat & $\begin{array}{c}\text { The offender } \\
\text { threatened the victim } \\
\text { offered assistance } \\
\text { to the victim }\end{array}$ \\
\hline Conversation & $\begin{array}{c}\text { The offender } \\
\text { engaged the victim } \\
\text { in conversation }\end{array}$ & ActedOnThreat & $\begin{array}{c}\text { The offender both } \\
\text { threatened the victim } \\
\text { and followed up on the } \\
\text { threat }\end{array}$ \\
\hline OneLiner & $\begin{array}{c}\text { The offender } \\
\text { spoke one line } \\
\text { before initiating } \\
\text { attack }\end{array}$ & $\begin{array}{c}\text { A tool or aid of some } \\
\text { kind was used to } \\
\text { facilitate the offence }\end{array}$ \\
\hline
\end{tabular}

Table 3: Convictions received by Offenders.

\begin{tabular}{ccc}
\hline Conviction & Count & Percentage \\
\hline Attempted child abduction/kidnap & 13 & $24.53 \%$ \\
\hline Rape & 12 & $22.64 \%$ \\
\hline Child abduction/Kidnap & 11 & $20.75 \%$ \\
\hline Sexual Assault & 6 & $11.32 \%$ \\
\hline Murder & 5 & $9.43 \%$ \\
\hline Attempted Murder & 1 & $1.89 \%$ \\
\hline Indecency with a child/Indecent Assault & 3 & $5.66 \%$ \\
\hline Assault & 3 & $5.66 \%$ \\
\hline attempted sexual assault & 1 & $1.89 \%$ \\
\hline Conspiracy to abduct & 1 & $1.89 \%$ \\
\hline
\end{tabular}

Table 4: Aggressive Control Variable Frequency 


\begin{tabular}{lcccccc}
\cline { 2 - 7 } Variable & \multicolumn{2}{c}{ Attempted } & \multicolumn{2}{c}{ Completed } & \multicolumn{2}{c}{ All Cases } \\
\cline { 2 - 7 } & Percentage & Count & Percentage & Count & Percentage & Count \\
\hline Grab & $40.60 \%$ & 13 & $40.40 \%$ & 23 & $46.15 \%$ & 36 \\
Front Loaded Control & $12.50 \%$ & 4 & $42.10 \%$ & 24 & $35.90 \%$ & 28 \\
Single line before attack & $9.40 \%$ & 3 & $11.00 \%$ & 6 & $11.54 \%$ & 9 \\
Tool & $25 \%$ & 8 & $49.10 \%$ & 28 & $46.15 \%$ & 36 \\
Improvised Tool & $9.40 \%$ & 3 & $31.60 \%$ & 18 & $26.92 \%$ & 21 \\
Brought Tool & $18.80 \%$ & 6 & $19.30 \%$ & 11 & $21.79 \%$ & 17 \\
Weapon & $15.60 \%$ & 5 & $22.80 \%$ & 13 & $23.08 \%$ & 18 \\
Ties & $3.10 \%$ & 1 & $24.60 \%$ & 14 & $19.23 \%$ & 15 \\
Vehicle & $31.30 \%$ & 10 & $42.10 \%$ & 24 & $43.59 \%$ & 34 \\
Threat & $18.80 \%$ & 6 & $40.40 \%$ & 23 & $37.18 \%$ & 29 \\
Acted on Threat & $3.10 \%$ & 1 & $26.30 \%$ & 15 & $20.51 \%$ & 16 \\
Rape & $6.30 \%$ & 2 & $70.20 \%$ & 40 & $53.85 \%$ & 42 \\
Assault & $31.30 \%$ & 10 & $57.90 \%$ & 33 & $55.13 \%$ & 43 \\
Multiple Offender & $12.50 \%$ & 4 & $12.30 \%$ & 7 & $14.10 \%$ & 11 \\
\hline
\end{tabular}

Table 5: Manipulative Control Variable Frequencies

\begin{tabular}{lcccccc}
\hline & \multicolumn{2}{c}{ Attempted } & \multicolumn{2}{c}{ Completed } & \multicolumn{2}{c}{ All Cases } \\
\cline { 2 - 7 } Variable & Percentage & Count & Percentage & Count & Percentage & Count \\
\hline Manipulate & $43.80 \%$ & 14 & $49.10 \%$ & 28 & $53.85 \%$ & 42 \\
Multiple Victims & $9.40 \%$ & 3 & $17.50 \%$ & 10 & $16.67 \%$ & 13 \\
Appeal to Authority & $12.50 \%$ & 4 & $14 \%$ & 8 & $15.38 \%$ & 12 \\
Incentive & $12.50 \%$ & 4 & $30 \%$ & 17 & $26.92 \%$ & 21 \\
Request For Assistance & $6.30 \%$ & 2 & $18 \%$ & 10 & $15.38 \%$ & 12 \\
Offer of Assistance & $12.50 \%$ & 4 & $14 \%$ & 8 & $15.38 \%$ & 12 \\
Conversation & $21.90 \%$ & 7 & $33 \%$ & 19 & $33.32 \%$ & 26 \\
\hline
\end{tabular}

